\title{
General Health status of workers among different workplaces in Qom Province, Iran
}

\author{
Alireza Koohpaei ${ }^{1}$, Mohammad Khandan ${ }^{2}$, Mahdi Gaeeni ${ }^{3}$, Somayeh Momenyan ${ }^{4}$
}

${ }^{1}$ Ph.D. of Occupational Health, Assistant Professor, Department of Occupational Health, Faculty of Health, Qom University of Medical Sciences, Qom, Iran

${ }^{2}$ M.Sc. of Ergonomics, Instructor, Department of Ergonomics, Faculty of Health, Qom University of Medical Sciences, Qom, Iran

${ }^{3}$ B.Sc. of Psychology, Pouyandegan Hafeze Salamat Co., Qom, Iran

${ }^{4}$ Ph.D. Candidate of Biostatistics, Department of Biostatistics, Paramedical sciences Faculty, Shahid Beheshti University of Medical Sciences, Tehran, Iran

\section{Type of article: Original}

\begin{abstract}
Introduction: In a healthy organization, psychological health and physical health are as important as production and productivity; and healthy workers have higher productivity. Regarding lack of information about workers' general health profile in Qom Province, this study aimed to assess and compare the staffs' general health and its components among different workplaces in 2014.

Methods: In a cross-sectional study, 2,276 employees working at 46 industries and organizations completed a standardized General Health Questionnaire (GHQ 28) and a demographic questionnaire. Data were analyzed using t-test, ANOVA, and Pearson product-moment correlation coefficient by IBM SPSS version 20.

Results: The mean age of the participants was $32.22( \pm 7.55)$ years. Seventy-nine point four percent of participants were married and the rest were single. Highest and lowest scores belonged to social dysfunction and depression, respectively. Also, total score of staffs' general health was $17.87 \pm 10.93$. The results showed that, in spite of the non-relationship between general health score difference among married and single personnel ( $\mathrm{p}>$ $0.05)$, there was a significant difference between men and women and among organizations and industries with regards to general health score $(\mathrm{p}<0.05)$, and drivers had the most difference with others. The relationship between workers' ages and GH was significant $(\mathrm{p}<0.05$, Pearson's bivariate correlation coefficient $=-0.05)$.

Conclusion: The findings of this study collectively indicated that participants had an acceptable condition for mental factors, such as depression, but not in viewpoints of social dysfunction. In other words, staffs' interfaces with circumstances and personal innovation/creativity in the workplaces are at risk. Altogether, the general health score in the studied population was suitable in its entirety.

Keywords: workplaces, mental health, GHQ-28, QOM Province, Iran
\end{abstract}

\section{Introduction}

Based on the World Health Organization's (WHO) definition, health is a state of complete physical, mental, and social well-being and not merely the absence of disease (1). Also, General Health (GH) as a sub-directory of the health system is the general condition of the body or mind with reference to soundness and vigor. On the other hand, $\mathrm{GH}$ is defined as systematic activities and social acts based on the prevention, Science \& Art for disease management, increasing expectancy of life and health promotion that lead to welfare $(2,3)$. In the organizational views, Health issues would be vital. Creating Healthy Organizations will help to strengthen the links between people and performance in humanly sustainable ways. In this situation, mangers would focus on workers' safety and health issues, which are equal to organizational productivity and financial benefits (4). Doubtless, healthy workforces are a key factor to performance of work and success (5).

\section{Corresponding author:}

Mohammad Khandan. Department of Ergonomics, Faculty of Health, Qom University of Medical Sciences, Qom, Iran. Tel: +98.2537842226, Fax:+98.2537833361, Email: mkhandan@muq.ac.ir

Received: August 08, 2015, Accepted: October 20, 2015, Published: December 2015

iThenticate screening: August 29, 2015, English editing: November 02, 2015, Quality control: November 11, 2015 (C) 2015 The Authors. This is an open access article under the terms of the Creative Commons Attribution-NonCommercialNoDerivs License, which permits use and distribution in any medium, provided the original work is properly cited, the use is non-commercial and no modifications or adaptations are made. 
Workers in their own workplaces are exposed to many different hazards and hazardous conditions that can threaten health and life. Although some hazards are less likely to happen in some work spaces than others, it's important to assess which hazards are most damaging to the organization and its employees (6). Apart from the chemical, physical, mechanical, biological, and ergonomic agents, spiritual pressure and mental tensions exist in workplaces. These factors and their effects on humans must be controlled. If anybody spent about one-third of their own day at work, it is necessary to assess and control adverse situations based on this fact, $(7,8)$. It should be noted that things that affect large portions of the employees really affect small- and medium-sized businesses more than large businesses.

Although some hazards are less likely to happen in some workplaces than others, it's important to assess which hazards are most damaging to employees. Some may pose more serious threats to employees' welfare, and still others will result in the most time lost or be the most costly. For example, ergonomic challenges lead to musculoskeletal disorders (MSD) $(9,10)$, physical or psychosocial factors result in cardiovascular diseases (11), and mental stressors create mental disorders and diseases (12). Also, the literature has shown meaningful relationships between different health components, social disturbances, and mental disorders. Anxiety and depression (13), quality of life (14), work absenteeism (15), mental load (16), psychosomatic symptoms (17), occupational dissatisfaction and burnouts (18), sleepiness (19), and sleep quality (20) are some examples of social and mental challenges. Besides, occupational disease and job accidents are very important conflicts (21). In some research, the relationship between health status and occupational accidents has been well documented (21-23).

Many factors can contribute to the creation of a general health profile for working communities (24). Job selection procedures, lifestyles, family-society interactions (25), educational and personal development (26), organizational culture and mental health planning (27), management procedure and job security (28), job and mental consultation (29), economic affluence (30), stress and anxiety management (31), spirituality, ethics, and formal or informal grouping are all factors that affect the general health of workers $(27,28,31)$. Employees with anxiety attacks (32), depression (32), severe stress (28), psychosomatic disorders and somatic signs $(33,34)$, chronic pain (35), social conflicts and sleep disturbance (15) can certainly not be productive and predictable as well as useful for their organizations and countries (36). Data were acquired from general health assessment in workers' communities in order to solve problems relating to lack of information in Iranian populations; it could be used by policy-makers and managers for integrated planning and work health promotion. One of the best procedures for mental status assessment is clinical experimentation. However, cost and complexity of this evaluation are considerable. Also, these experiments are time-consuming and thus their ability for large-scale designs is limited. Nowadays, a simple and fluent tool, the Goldberg questionnaire, is recommended (37). Based on this tool, Noorbala et al. reported that between $11.9 \%$ and $23.8 \%$ of the Iranian adult population suffers mental disorders that require mental health care (38). Some studies also have focused on Iranian workers, such as forest workers (39), Petrochemical shift workers (40), Metal workers (41, 42), Miners (15), and health care workers (43). However, these studies generally focused on a specific industry. Accordingly, it seems there was no possibility of generalizing their results to other industries and working communities in Iran. The general objective of this research was to determine the general health status of workers among different workplaces in Qom Province, Iran, in 2014. This Province was selected because of 1) lack of related information about general health profile and mental health status among its working community as well as in Iran, 2) according to the latest statistics published in Iran (44), Qom Province has the highest rate of population growth in the country and one of the reasons has been migration and accumulation of different ethnic working groups. Most of the immigrants were faced with many challenges and their mental health or other lifestyle indices were not suitable (45), and 3) a wide variety of small and medium-scale industries in the Province. Technological changes are influencing the health status of employees all over the world (46). On this basis, since Qom is one of the rapidly industrialized provinces in Iran (44) and in order to evaluate the impact of this change on the health of workers, this study was designed. The outcome of this study would be occupational safety and health promotion, disease management, accident control in the workplaces, aiding the related organizations for better performance, and policy-making through appropriate decision-making. Such information may as well be used for efficient national or local mental health intervention.

\section{Material and Methods}

\subsection{Research setting and sampling}

This cross-sectional study was designed and carried out among 2,276 workers who were working in 37 companies, organizations, and industries. These workers were selected randomly. The fields of research were located at Qom Province in the central part of Iran in 2014. 


\subsection{Measurement tool}

The demographic questionnaire focused on age, gender, and marital status, and the main tool for our study was the general health questionnaire (GHQ-28) that was introduced by Goldberg. This questionnaire is a valid and reliable tool for the determination of mental health status between different societies and communities. GHQ has four subscales: somatic symptoms, sleeplessness, social dysfunction, and depression. For scaling of the questionnaire, a Likert technique was used, and scoring of questions was done in a 4-grade style (1, 2, 3 and 4). Lower scores indicated higher level of mental health and vice versa. Based on the literature, the ultimate scores for all workers were calculated to be 84 , and a cut-off point of 23 was selected for evaluation purposes. Hence, people with scores higher than 23 were considered suspects of disorder (47). Also, for sub-scales, the selected cut-off point was equal to 6. Based on this fact, participants with a score lower than 6 were considered as healthy workers (48). The rrange of scores in all of the sub-scales was defined between 0 and 21.

\subsection{Validity and reliability}

As mentioned before, GHQ is a valid and reliable tool. In one research effort, the correlation factor between GHQ and the Minnesota questionnaire was reported to be equal to 0.54 (49). Other works have revealed that this tool was reliable, based on the Cronbach's alpha value of 0.93 (50). Regarding the Persian version of this questionnaire, Taghavi et al. carried out the survey of validity and reliability and approved both (51).

\subsection{Ethical consideration}

The results were collected and reported based on the approved ethical code of Qom University of Medical Sciences. All workers were informed that inclusion in and exclusion from the study were voluntary. All names and other related information of the participants were considered private and confidential.

\subsection{Data analysis}

Statistical analyses, such as independent samples t-test, one-way analysis of variance (ANOVA), and Pearson correlation tests were used appropriately for data evaluation by SPSS-IBM version 20 .

\section{Results}

\subsection{General description}

Most of the respondents (2143 out of 2,276) were males (94.2\%), and 1,808 of them (79.4\%) were married. Mean and standard deviation of ages were reported as $32.22 \pm 7.55$. Employees of 37 companies and organizations who participated in this study based on fields and types of activities were divided into nine groups. With regards to the table, the food industry group outweighed the other groups with $27.9 \%$ of samples. Metal industries, which had 439 workers $(19.3 \%)$ in the research and construction industry was in minority $(n=112$ and $4.9 \%)$.

\subsection{General health $(G H)$}

After the returned surveys were examined and filtered for incomplete items, all of them were passed, and the total of 2276 responses was used in the analysis. The results showed that general health had a mean score of 17.87 and its SD was measured as 10.93. The services group had the lowest total general health score $(15.60 \pm 9.46)$, and, in contrast, drivers had the highest $(21.45 \pm 12.88)$. Table 1 depicts the mean and SD of total GH and its scales among nine different groups of occupations and all workers in the study. Social dysfunction and depression got 6.08 and 2.55, respectively, as their mean scores as the highest and lowest. About the depression scale, people who worked in the services group had mean $\pm \mathrm{SD}$ of $1.85 \pm 2.89$ (lowest score), and the food and construction industries were next. Welders $(3.39 \pm 3.54)$, distribution, and chemicals had the most signs of depression. Social dysfunction in two groups of services $(5.66 \pm 2.66)$ and welding $(6.91 \pm 3.33)$ differed from the others. Sleeplessness scale had its least score in the services group $(4.32 \pm 3.92)$ and in the food and construction industries. Considering 6 and 23 as cut-off points of the four scales and total GH (52), respectively, eight organizations (out of 37, 21.6\%) in sleeplessness, and 16 in social dysfunctions (43.2\%) were in unhealthy status. But, none of the 37 organizations was unhealthy in somatic symptoms, depression, or total general health. With respect to the nine industrial groups in Table 2 , employees in two groups of drivers and chemical industry were unacceptable in sleeplessness. Furthermore, welders, drivers, and workers in assembly and chemical industries had a mean score of more than the related cut-off point in social dysfunction. Additional information was gathered in Table 2. Five variable differentiations among the nine groups were analyzed using ANOVA and between males and females and were based on marital status, independent t-test was applied, and the related results are presented in Table 3. GH and its scales, except for social dysfunction, had a significant difference with regards to gender $(\mathrm{p}<0.05)$ and occupational groups $(\mathrm{p}<0.01)$ and drivers had the 
most difference with others. On the other hand, social dysfunction and depression differed between married and single respondents $(\mathrm{p}<0.05)$. Finally, relationship between workers' age and GH and its sub-factors were assessed by the Pearson correlation test, and those were significant in all cases $(p<0.05$, Pearson's bivariate correlation coefficient $(p$-coefficient $)=-0.05)$ ). General health and its four scales were significantly correlated $(p<0.01)$ and acceptable, and the highest coefficient was related to sleeplessness $(0.88)$, and the lowest coefficient was for social dysfunction (0.73).

Table 1. General health and its scales description in different job sectors, Mean (SD), (N=2276)

\begin{tabular}{|l|l|l|l|l|l|}
\hline Occupational groups (n) & GH & \multicolumn{3}{|l|}{ General health scales } \\
\cline { 3 - 7 } & & $\begin{array}{l}\text { Somatic } \\
\text { symptoms }\end{array}$ & Sleeplessness & $\begin{array}{l}\text { Social } \\
\text { dysfunction }\end{array}$ & Depression \\
\hline Services (259) & $15.60(9.46)$ & $3.76(2.88)$ & $4.32(3.92)$ & $5.66(2.66)$ & $1.85(2.89)$ \\
\hline Assembly (237) & $17.86(10.95)$ & $3.79(2.99)$ & $5.05(3.99)$ & $6.27(3.26)$ & $2.76(3.38)$ \\
\hline Distribution (125) & $17.52(10.21)$ & $3.96(3.09)$ & $4.77(3.88)$ & $5.82(2.42)$ & $2.97(3.57)$ \\
\hline Metal working (439) & $17.85(10.69)$ & $4.24(3.17)$ & $4.99(3.94)$ & $5.91(2.84)$ & $2.68(3.38)$ \\
\hline Welding (138) & $21.41(9.98)$ & $5.28(2.91)$ & $5.83(3.71)$ & $6.91(3.33)$ & $3.39(3.54)$ \\
\hline Food sector (639) & $16.56(10.54)$ & $3.87(3.10)$ & $4.50(3.99)$ & $5.88(2.82)$ & $2.31(3.44)$ \\
\hline Chemical (116) & $20.59(12.12)$ & $5.11(3.91)$ & $6.16(4.47)$ & $6.44(3.04)$ & $2.87(3.88)$ \\
\hline Construction (112) & $16.92(10.87)$ & $3.89(3.22)$ & $4.61(4.46)$ & $5.89(2.76)$ & $2.53(3.22)$ \\
\hline Driving (214) & $21.45(12.88)$ & $5.71(3.78)$ & $6.22(4.26)$ & $6.82(3.25)$ & $2.69(3.77)$ \\
\hline Total (2276) & $17.87(10.93)$ & $4.25(3.25)$ & $4.98(4.05)$ & $6.08(2.94)$ & $2.55(3.44)$ \\
\hline
\end{tabular}

Table 2. Frequency (percentage) of healthy ones among workers, organizations and groups

\begin{tabular}{|l|l|l|l|}
\hline Factors & Workers $(\mathrm{n}=2276)$ & Organizations $(\mathrm{n}=37)$ & Occupational groups $(\mathrm{n}=9)$ \\
\hline Somatic symptoms & $1817(79.8)$ & 0 & 0 \\
\hline Sleeplessness & $1597(70.2)$ & $8(21.6)$ & $2(22.22)$ \\
\hline Social dysfunction & $1372(60.3)$ & $16(43.2)$ & $4(44.44)$ \\
\hline Depression & $1990(87.4)$ & 0 & 0 \\
\hline GH & $1714(75.3)$ & 0 & 0 \\
\hline
\end{tabular}

Table 3. Comparing GH and its scales scores among occupational groups and between sex and marital status groups

\begin{tabular}{|l|l|l|l|l|l|l|}
\hline \multicolumn{2}{|l|}{ Comparison group } & \multirow{2}{*}{ GH } & General health scales & \multicolumn{2}{l|}{} \\
\cline { 4 - 7 } & & Somatic symptoms & Sleeplessness & Social dysfunction & Depression \\
\hline \multirow{3}{*}{ Sex } & Men & 17.63 & 4.14 & 4.93 & 6.06 & 2.50 \\
\cline { 2 - 7 } & Women & 21.64 & 5.99 & 5.84 & 6.48 & 3.32 \\
\cline { 2 - 7 } & $\mathrm{P}$ & 0.001 & 0.001 & 0.011 & 0.105 & 0.008 \\
\hline \multirow{3}{*}{ Marital status } & Married & 17.65 & 4.25 & 5.00 & 6.01 & 2.38 \\
\cline { 2 - 7 } & Single & 18.70 & 4.25 & 4.90 & 6.34 & 0.21 \\
\cline { 2 - 6 } & $\mathrm{P}$ & 0.08 & 0.553 & 0.212 & 0.043 & 0.001 \\
\hline
\end{tabular}

\section{Discussion}

This study made it clear that men are susceptible to anxiety, sleep disorder, and depression. Scientific findings depict that the mental health of male workers has been neglected (53). Also, care should be taken about females at work. Women are more at risk of work-related injuries and accidents (54). This sort of employees would experience more mental reactions in workplaces due to some physiological limitations, and their multiple roles in families and societies under stress will be more likely to result in anxiety and depression. Total general health and its four scales scores compared among nine groups of occupations by ANOVA, and the outcomes showed that all five factors were significantly different from a statistical perspective $(\mathrm{p}<0.01)$. Besides, $t$-test results depicted that all five studied factors, except social dysfunction, differed between men and women $(\mathrm{p}<0.05)$; males had lower scores than females in all significant cases. On the other hand, just depression was different between married and single workers, with married workers getting lower scores. A previous study among women showed that $26.7 \%$ of studied females had somatic symptoms. Thirty five percent suffered from sleeplessness, and $45 \%$ of them were confronted with problems in social functions (54). In this research, women had higher scores. In other words, females were more likely to have mental disorders. The mean of all sub-factors and the total score of GH (21.64) were very close 
to the cut-off points, i.e., 6 and 23, with the meaning that outcomes are really on the borderline. Therefore, we suggested a periodic assessment of the mental health of female workers. It is obviously clear from the information in Table 4 that marriage due to the provision of a positive climate with better psychological status for employees affected depression, and those who were married had better conditions on this scale than single workers. This finding was in line with Shahrokhi’s study (54).

The relationship between stresses resulted from outside the organization, especially at home, with the total stress of workers, general health, and occupational mental disorders that directly reduce productivity, and this was one the most important issues that researchers recently have taken into account (25). Based on research conducted by Fan et al. (25), the main cause of stress in men and women was domestic, along with low job security, and social support at work; each of these was correlated strongly with anxiety and depression. The results of a cohort study that included 7,482 people and was about fatigue at workplaces, indicated that $8.2 \%$ of men and $10 \%$ of women had signs of anxiety, and $7.1 \%$ males and $6.2 \%$ of females were depressed in their work environments (55). That result about anxiety of women was more relevant to this study. Work capacity was analyzed by deductive content analysis in a qualitative study, and it illustrated the effect of anxiety and depression on time management and provision of negative job demands; besides, it makes workers panic, which reduced their work capacity, so workers tended towards burnout $(56,57)$. Emotional exhaustion of stressed workers boosted 10 more times in return for one score increase in GH (58). Working communities in Iran, the same as in other countries, are faced with some challenges in the workplaces that have not been addressed extensively in scientific documents. Sleep disorders, quality of life, and absence from the work phenomena are from these challenges. Sleeplessness were measured and reported among results for workers of Qom Province. Results from many researchers have indicated that anxiety and depression lead to sleep problems, decreased quality of life of workers, and work absence (59-61). It is noticeable that absence from work increases with increase in age and when general health is at stake (14). These cases need to be assessed more in Iran. Therefore, in various jobs and with respect to organizational culture and climate, employees revealed different levels of sub-factors. As an example, drivers had the most problems in the total score of GH; it was expected because of low levels of social supports and job security.

Despite the fact that some studies showed a relationship between anxiety, depression, and sleep disorder with age $(61,14)$, it was not significant in this study. This difference can be as a result of young participants in our study. The results can be explained in this way, i.e., the increase in work experience will cause a reduction in general health. In addition, sleeplessness and somatic symptoms had the highest relationships with total GH and were totally the same as the outcome of Nagyova et al.'s research (62). Twenty point two percent (20.2\%) of workers reported physical symptoms, such as pain. Relation between somatic pains and mental factors was too complicated and required more attention. Relationship of burnout and cardiovascular diseases as two criteria of mental pressures and physical problems was considered (63). The findings illustrated a close relationship between mental factors and somatic disorders. One more thing, only $39.7 \%$ of studied workers did not report social dysfunctions. This sort of problem was reported in work communities, so their prevention and handling required caring about psycho-social factors at workplaces (55). It should be noted that this survey was conducted using the 28-item General Health Questionnaire, which was not a systematic clinical interview, and it was unable to evaluate different disorders. Also, the industries were located in different locations of the Province, and they parted ways with those that needed too much time to gather data. These were the main limitations of the study.

\section{Conclusions}

Generally, workers' general health was in acceptable state among the studied organizations. Although $24.7 \%$ of respondents suffered from poor general health status, it is vividly clear that conditions should be improved to keep and increase efficiency and working capacity of workers in the framework of supportive plans. On the other side, social support, reward system, job enrichment and acceptable behavior that are capable of helping employees to behave more positively and to dominant job stress can reduce mental health issues at workplaces. Therefore, careful thoughts are recommended about them in Iranian organizations. It is also recommended that considerations be made regarding ethnic variability in other similar studies.

\section{Acknowledgments:}

This manuscript was the result of a researcher-funded study. The authors would like to thank all of the honorable managers and staff members in the companies for their gracious cooperation. 


\section{Conflict of Interest:}

There is no conflict of interest to be declared.

\section{Authors' contributions:}

All authors contributed to this project and article equally. All authors read and approved the final manuscript.

\section{References}

1) Organization WHO. Preamble to the Constitution of the World Health Organization, 1948. The First Ten Years of the World Health Organization. 2004.

2) Bolhari J. Mental Health. 3rd ed. Tehran: Boshra publication; 2007 (Persian)

3) Shi L, Johnson JA. Novick and Morrow's Public Health Administration: principle for population-based management. 3rd ed. Burlington: Jones \& Bartlett Learning; 2014

4) Mohr WK, Petti TA, Mohr BD. Adverse effects associated with physical restraint. Canadian Journal of Psychiatry. 2003; 48(5): 330-7. PMid:12866339

5) Amini A, Hejazi A. analysis and assessment of health and hygiene role on workforce productivity improvement in economics of Iran. Iranian Journal of Economic Research. 2007; 9(30): 137-163.

6) Sadegi Naeini H, Rismanchian M. Determination of a quantitative job severity score value for health hazards in industry. Iran Occupational Health. 2007; 4(3-4): 44-48. (Persian)

7) Ahmadi S. Study job burnout educational managers in triple amputation esfahan. Journal Research Esfahan University Period. 2002; 13: 275-84. (Persian)

8) Tirgar A, Koohpaei A, Allahyari T. Occupational health. Andishe Rafee Publications: Iran. 2007; p: 10. (Persian)

9) Sommerich CM, McGlothlin JD, Marras WS. Occupational risk factors associated with soft tissue disorders of the shoulder: a review of recent investigations in the literature. Ergonomics. 1993; 36(6): 697-717. Doi: 10.1080/00140139308967931, PMID: 8513776

10) Sharafi N, Gharibi F, Khoobi J. Muskuluskeletal disorders prevance and its relationship with working postures among carpet weavers in Sanadaj. Scientific journal of Kurdestan university of medical sciences. 2014; 19(4): 1-9. (Persian)

11) Kristensen TS. Cardiovascular diseases and the work environment: a critical review of the epidemiologic literature on nonchemical factors. Scandinavian journal of work, environment \& health. 1989; 165-79. PMID: 2675305

12) Van der Doef M, Maes S. The job demand-control (-support) model and psychological well-being: a review of 20 years of empirical research. Work \& stress. 1999; 13(2): 87-114. DOI:10.1080/026783799296084.

13) Halvani G, Morowati sharifabad M, Baghiani moghadam M. Determining the general health status of workers of Kuushk mines. koomesh. 2007; 8 (4): 261-268. (Persian)

14) Bouwmans CAM, Vemer P, Van Straten A, Tan SS, Hakkaart L. Health related quality of life and productivity losses in patient with depression and anxiety disorders. Journal of Occupational and Environmental Medicine, 2014; 56(4): 420-424. doi: 10.1097/JOM.0000000000000112. PMID: 24709765

15) Zare S, Shabani N, Babaei Heydarabadi A. Investigation of the relationship between general health and workers' sleep quality and work incidence in Gole Gohar mineral industries Co., Sirjan. Scientific Journal of Ilam University of Medical Sciences. 2013; 21(2): 112-119. (Persian)

16) Giahi O, Darvishi E, Ajbar zade M, Shahsavari S. Assessment of mental load risk in muskuluskeletal among bank staffs in Kurdestan. Scientific journal of Kurdestan university of medical sciences. 2014; 19 (4): 36-45. (Persian)

17) Wang Y, Xie J, Yang F, Wu S, Wang H, Zhang X, et al. The prevalence of primary headache disorders and their associated factors among nursing staff in North China. The Journal of Headache and Pain. 2015; 16:4. doi: 10.1186/1129-2377-16-4. PMID: 25582043. PMCID: PMC4405508

18) Asghari M, Zakerian A, Monazam MR, Abbassinia M, Mohamadiam Y, Rahmani A. The relationship between job satisfaction with general health and job burnout workers in an automotive industry. Health and Safety at Work. 2013; 2(4): 51-60. doi: 10.3325/cmj.2008.3.364. PMCID: PMC2443621

19) Farvaresh E, Monazam MR, Abbassinia M. Investigation the relationship between sleepiness and general health of shift workers in the automobile industry. Journal of North Khorasan University of Medical Sciences. 2012; 4(2): 221-226. (Persian)

20) Pereira D, Elfering A. Social stressors at work, sleep quality and psychosomatic health complaints-A longitudinal ambulatory field study. Stress Health. 2014; 30: 43-52. doi: 10.1002/smi.2494. doi: 10.1097/01.jom.0000128150.94272.12, PMID: 23824588 
21) Ghamari F, Mohammadfam I, Mohammadbeigi A, Ebrahimi H, Khodayari M. Determination of effective risk factors in incidence of occupational accidents in one of the large metal industries, Arak (2005-2007). Iran Occupational Health. 2013; 9(4): 89-96. (Persian)

22) Swaen GMH, Van Amelsvoort L, Bültmann U, Slangen J, Kant I. Psychosocial work characteristics as risk factors for being injured in an occupational accident. Journal of Occupational and Environmental Medicine. 2004; 46(6): 521-7. PMID: 15213513

23) Suzuki K, Ohida T, Kaneita Y, Yokoyama E, Miyake T, Harano S, et al. Mental health status, shift work, and occupational accidents among hospital nurses in Japan. Journal of occupational health. 2004; 46(6): 448-54. PMID: 15613767

24) Bhui KS, Dinos S, Stansfeld SA, White PD. A Synthesis of the evidence for managing stress at work: A review of the reviews reporting on anxiety, depression, and absenteeism. J Environ Public Health. 2012; Article ID 515874. doi: 10.1155/2012/515874

25) Fan LB, Blumenthal JA, Watkins LL, Sherwood A. Work and home stress: associations with anxiety and depression symptoms. Occup Med (Lond). 2015; 65(2): 110-6. doi: 10.1093/occmed/kqu181. . PMID: 25589707, PMCID: PMC4402380.

26) Tung CY, Chang CC, Ming JL, Chao KP. Occupational hazards education for nursing staff through webbased learning. Int J Environ Res Public Health. 2014; 11: 13035-46. doi: 10.3390/ijerph111213035. PMID: 25514154, PMCID: PMC4276660.

27) De Ruijter RAG, Stegenga B, Schaub RMH, Reneman MF, Middel B. Determinants of physical and mental health complaints in dentists: a systematic review. Community Dent Oral Epidemiol. 2015; 43; 86-96. doi: 10.1111/cdoe.12122. PMID: 25178388

28) Khamisa N, Oldenburg B, Peltzer K, Ilic D. Work related stress, burnout, job satisfaction and general health of nurses. Int J Environ Res Public Health. 2015; 12: 652-66. doi: 10.3390/ijerph120100652, PMID: 25588157. PMCID: PMC4306884.

29) Rothermund E, Kilian R, Hoelzer M, Annemarie Rieger M, Guendel H. Psychosomatic consultation in the workplace: do we reach different users by changing the context? BMC Health Serv Res. 2014; 14(Suppl 2): P105. doi: 10.1186/1472-6963-14-S2-P105, PMCID: PMC4122877.

30) Miyaki K, Song Y, Taneichi S, Tsutsumi A, Hashimoto H, Kawakami N, et al. Socioeconomic status is significantly associated with dietary salt intakes and blood pressure in japanese workers (J-HOPE Study). Int J Environ Res Public Health. 2013; 10: 980-93. doi: 10.3390/ijerph10030980, PMCID: PMC3709298.

31) Jensena JC, Haahra JP, Frosta P, Andersen JH. The significance of health anxiety and somatization in careseeking for back and upper extremity pain. Fam Pract. 2012; 29: 86-95. doi: 10.1093/fampra/cmr046, PMID: 21817088.

32) Nieuwenhuijsen K, de Boer AG, Verbeek JH, Blonk RW, van Dijk FJ. The depression anxiety stress scales (DASS): detecting anxiety disorder and depression in employees absent from work because of mental health problems. Occup Environ Med. 2003; 60(Suppl 1): i77-82. PMID: 12782751, PMCID: PMC1765723.

33) Klussmann A, Gebhardt H, Liebers F, Rieger MA. Musculoskeletal symptoms of the upper extremities and the neck: A cross-sectional study on prevalence and symptom-predicting factors at visual display terminal (VDT) workstations. BMC Musculoskelet Disord. 2008; 9: 96. doi: 10.1186/1471-2474-9-96, PMID: 18588677, PMCID: PMC2474829.

34) Luiza M, Comper C, Padula RS. The effectiveness of job rotation to prevent work-related musculoskeletal disorders: protocol of a cluster randomized clinical trial. BMC Musculoskelet Disord. 2014; 15: 170. doi: 10.1186/1471-2474-15-170, PMID: 24885958, PMCID: PMC4040481.

35) Alibeige N, Noorgostar S, Bidari A, Sadeghi Sh, Shahgholi L. Mental health and psychological disorders of pain among workers with chronic backpain in a industrial company. Payesh. 2008; 7(2): 247-52

36) Okwaraji FE, Aguwa EN. Burnout, psychological distress and job satisfaction among secondary school teachers in Enugu, South East Nigeria. J Psychiatry. 2015; 18:1. doi: 10.4172/Psychiatry. 1000198.

37) Daneshmandi H, Choobineh A, RajaeiFard A. The investigation of association between psychological health and maximum aerobic capacity in male workers of industrial sector of Shiraz.. J Ergon. 2013; 1(1).

38) Noorbala AA, Bagheri Yazdi SA, Yasamy MT, Mohammad K. Mental health survey of the adult population in Iran.. Br J Psychiatry. 2003; 184(1): 70-3. doi: 10.1192/bjp.184.1.70, PMID: 14702230.

39) Lotfalian M, Emadian SF, Riahi Far N, Salimi M, Sheikh Moonesi F. Occupational stress impact on mental health status of forest workers. Middle East J Sci Res. 2012; 11(10): 1361-5. doi: 10.5829/idosi.mejsr.2012.11.10.64170. 
40) Bazazan A, Rasoulzadeh Y, Dianat I, Safaiyan A, Mombeini Z, Shiravand E. Demographic factors and their relation to fatigue and mental disorders in 12-Hour petrochemical shift workers. Health Promot Perspect. 2014; 4(2): 165-72. doi: 10.5681/hpp.2014.022, PMCID: PMC4300442.

41) Amidi Mazaheri M. Comparison of temporary and permanent workers' job satisfaction and mental health in Isfahan steel company.. Adv Ind Eng Manag. 2014; 3(1): 89-94. doi: 10.7508/AIEM-V3-N1-89-94.

42) Rostami R, Zamanian $Z$, Hasanzade J. Investigation of the effect of noise exposure in the workplace on the general health of steel industry workers.. Int J Occup Hyg. 2013; 5(2): 53-5. doi: 2008-5435/13/52-53-55.

43) Tajvar A, Nasl Saraji G, Ghanbarnejad A, Omidi L, Seyed Hosseini SS, Salehi Sahl Abadi A. Occupational stress and mental health among nurses in a medical intensive care unit of a general hospital in Bandar Abbas in 2013. Electron Physician. 2015; 7(3): 1108-1113, doi: 10.14661/2015.1108-1113, PMCID: PMC4574696.

44) Statistical centre of Iran, Iran statistical yearbook, Iran statitistical yearbook 2012-2013. Available from: www.amar.org.ir.

45) Sohrabi MR. Why Focusing on Social Determinants of Health? SDH. 2015; 1(1): 1.

46) Price RH. Changing Life Trajectories, Employment Challenges and Worker Health in Global Perspective, Sustainable Working Lives, Aligning Perspectives on Health, Safety and Well-Being. Springer; 2015. doi: 10.1007/978-94-017-9798-6 1.

47) Noorbala AA, Bagheri yazdi SA, Mohammad K. The validation of general health questionnaire- 28 as a psychiatric screening tool.. Hakim Res J. 2009; 11: 47-53.

48) Nastiezaie N, Vaezi M, Molazahi A, Moghadam M. The relationship between job burnout and public health of telecommunication central office personnel in Zahedan. Toloo-E-Behdasht. 2009; 7: 49-56.

49) Chan DW, Chan TSC. Reliability, validity and the structure of the General Health Questionnaire in an Chinese version context. Psychol Med. 1983; 13: 363-72. PMID: 6878523.

50) Chan DW. The Chinese version of the General Health Questionnaire: Does language make a difference? Psychol Med. 1985; 15: 147-55. PMID: 3991829.

51) Taghavi M. Validity and reliability of general helth questionnaire assessment. Psychology. 2001; 20: 38198.

52) Biglar M, Hayati Y, Rahmani H, Rajabnezhad Z, Dargahi H. Study of general health among Tehran university of medical sciences hospital's administrators. payavard. 2014; 8(1): 13-24.

53) Shafer K, Wendt D. Men's mental health: A call to social workers. Social Work Journal. 2015. doi: 10.1093/sw/swu061.

54) Shahrokhi A. General health status of female workers in Qazvin factories. The Journal of Qazvin Univ of Med Sci. 2003; 28: 32-35.

55) Andrea H, Bultmann U, Beurskens JHM, Swaen GMH, Vanschayck CP, Kant IJ. Anxiety and depression in the working population using the HAD scale--psychometrics, prevalence and relationships with psychosocial work characteristics. Soc Psychiatry Psychiatr Epidemiol. 2004; 39(8): 637-46. PMID: 15300374.

56) Bertilsson M, Love J, Ahlborg G, Hensing G. Health care professionals experience based understanding of individual's capacity to work while depressed and anxious. Scand J Occup Ther. 2015; 22(2): 126-36. doi: 10.3109/11038128.2014.985607, PMID: 25581065.

57) Guveli H. Oncology staff: burnout, job satisfaction and coping with stress. Psychooncology. 2015; 24(8): 926-31. doi: 10.1002/pon.3743, PMID: 25640592.

58) Bianchi R. Burnout Depression overlap: A review. Clin Psychol Rev. 2015; 36: 28-41. doi: 10.1016/j.cpr.2015.01.004, PMID: 25638755.

59) Haslam C, Atkinson S, Brown SS, Haslam RA. Anxiety and depression in the workplace: effect on the endividual and organization. J Affect Disord. 2005; 88(2): 209-15, PMID: 16122810.

60) Parkes KR. Sleep patterns of offshore day workers in relation to overtime work and age. Appl Ergon. 2015; 48: 232-9. doi:10.1016/j.apergo.2014.12.004.

61) Parkes KR. Shift rotation, overtime, age and anxiety as predictor of offshore sleep pattern. J Occup Health Psychol. 2015; 20(1): 27-39. doi: 10.1037/a0038164, PMID: 25347685.

62) Nagyova I, Krol B, Szilasiova A, Stewart RE, Dijk JP, Heuvel WJA. General Health Questionnaire-28: psychometric evaluation of the Slovak version. Stud Psychol. 2000; 42(4): $351-61$.

63) Toker S, Shirom A, Shapira I, Berliner S, Melamed S. The association between burnout, depression, anxiety and inflammation biomarkers: C-Reactive protein and fibrinogen in men and women. J Occup Health Psychol. 2005; 10(4): 344-62. PMID: 16248685. 